\title{
GATEEKEEPING PROCESS DALAM CITIZEN JOURNALISM BERKAITAN DENGAN PARTISIPASI MASYARAKAT DALAM MENYAMPAIKAN INFORMASI LALULINTAS DI RADIO IDOLA FM SEMARANG
}

\author{
Oleh : \\ Nora Prima Wardani Putri \\ (noraprimawardaniputri88@gmail.com) \\ (Mahasiswa S1 Program Studi Ilmu Komunikasi Universitas Semarang)
}

\begin{abstract}
This research was made to gain the information how the gate keeping process in Idola Radio works in public journalism responds that give informations by telephone or sms to Idola Radio.

This research base on the theory how the gate keeping process decides if the information proper or not to deliver into news and also the basic concept of citizen journalism that carry out by the people themselve who will give the information such as a reporter.

The methods that use in this research are qualitative description and perspective interactive. This research was made in FM Idola Radio Semarang and the resource was the staff who may concern.

From this research can be take a conclusion than the gatekeeper take a role to classify the information from public who act by the Program Manager, news supervisor and reporters. The Gatekeeper is the main point in every broadcast. It has a big role to select every news or informations before they put on the broadcast room to be on air.
\end{abstract}

Keywords : Gate keeping Process, Citizen Journalism, News Selection

\section{Pendahuluan}

Berkembangnya media massa saat ini membuat informasi menjadi sangat penting untuk diketahui oleh khalayak. Oleh karena itu semua pembuat informasi media massa terus terpacu untuk melakukan perubahan untuk mengikuti perkembangan jaman. Sementara itu, media massa saat ini sangat banyak jenisnya. Ada 3 jenis yaitu media cetak seperti (koran, majalah dan tabloid), media elektronik seperti (televisi dan radio), serta media online. Informasi yang di sampaikan di media masa pada umumnya dinilai masyarakat memiliki kredibilitas yang tinggi, sehingga apa yang diungkapkan dianggap suatu kebenaran yang ada di masyarakat. Karena itu media massa dapat dimanfaatkan untuk menyalurkan pesan atau aspirasi atau kritik dari berbagai pihak, baik masyarakat, organisasi atau pemerintah.

Informasi yang diperoleh perusahaan media massa didapat dari hasil peliputan wartawan atau reporter di lapangan. Wartawan melakukan liputan di lapangan untuk mengumpulkan data-data atau informasi dari sebuah peristiwa yang terjadi. Namun tidak semua wartawan dapat melakukan peliputan ditempat kejadian secara langsung, dikarenakan keterbatasan jarak ataupun waktu, sehingga masyarakatpun bisa memberikan informasi untuk disampaikan kepada media agar dapat di muat atau disiarkankan di media 
massa. Seperti sekarang ini dunia jurnalisme berubah, semua orang bisa menjadi jurnalis, bahkan hanya bermodalkan sebuah telepon seluler saja. Ini yang memunculkan istilah citizen journalism atau bahasa sederhananya jurnalis warga. Banyak pengertian tentang citizen journalism dari berbagai sumber satu diantaranya adalah (Shayne Bowman dan Chris Willis, 2003: 9) menyatakan : citizen journalism atau jurnalisme warga identik dengan peran aktif warga dalam proses pengumpulan pelaporan, analisis, diseminasi berita dan informasi. Hal ini memungkinkan masyarakat menyampaikan sebuah berita ke redaksi tanpa melalui wartawan. Sehingga wartawan tidak dapat mengakui bahwa dia yang pertama kali tau tentang suatu peristiwa. Sebab peristiwa yang terjadi diketahui pertama kali oleh publik.

Citizen journalism (jurnalis warga) pada umumnya adalah warga biasa yang menjalankan fungsi selayaknya jurnalis profesional yang menggunakan Channel media baru yaitu internet untuk menyebarkan berita yang mereka dapat.sedangkan keberadaan jurnalisme warga di Radio Idola FM Semarang merupakan sebuah konstribusi aktif dari pendengar setianya yang ingin berbagi informasi yang mereka lihat. Mereka menyampaikan informasi tersebut dengan cara menghubungi redaksi Radio Idola FM. Kemudian informasi tersebut disampaikan kepada gatekeeper untuk kemudian dikonfirmasi kebenarannya. Jika memang berita tersebut layak siar maka Radio Idola akan menghubungi kembali narasumber tersebut untuk menceritakan kejadian tersebut secara live.

Bagaimana apresiasi redaksi Radio Idola FM terhadap masyarakat yang menyampaikan informasi ke Radio Idola FM kaitannya dengan jurnalisme warga? Dan Bagaimana proses seleksi berita dan apa yang mempengaruhi seleksi berita terkait dengan citizen journalism tersebut?

\section{Tinjauan Pustaka \\ Gate keeping Process}

Gatekeeping adalah proses menentukan konten apa yang akan muncul di media.Menurut Shoemaker proses gatekeeping dibagi menjadi lima level, antara lain:

a Level Individu

Pada level ini Shoemaker menekankan pada pentingnya values yang dapat diartikan sebagai prinsip etis dan ideal mengenai 'apa seharusnya' (Bruce dan Yearley, 2006: 314). Shoemaker sendiri lebih banyak mencontohkan value tersebut dalam konteks Amerika, dimana jurnalis di sana dikatakan mengadopsi ide ethnosentrisme, altruistic democracy, responsible capitalism (Shoemaker, 1991: 43).

\section{b Level Rutinitas Komunikasi}

Rutinitas komunikasi atau organisasi di sini adalah praktik-praktik pekerja media dalam melakukan pekerjaan mereka yang telah terutinisasi, dilakukan berulang-ulang, dan telah terpola (Shoemaker and Reese, 1996: 105). Ruitinitas tersebut tidak hanya hadir dalam proses pencarian, pemrosesan, dan transmisi berita dalam media massa (contohnya deadline, piramida terbalik) namun juga dalam komunikasi interpersonal (contohnya adanya beberapa kata atau isu yang di anggap tidak pantas untuk ditampilkan) (Shoemaker, 1991: 48).

c Level Organisasional

Menurut Shoemaker level organisasional menjadi penting karena organisasi-lah yang menentukan siapa yang mereka pekerjakan dan aturan 
mana yang diterapkan. Menurut perspektif organisasi seorang gatekeeper yang sukses adalah orang yang dapat secara sempurna merepresentasikan kepentingan organisasi tersebut (Shoemaker, 1991: 53). Kemampuan untuk mempekerjakan dan memecat orang ini bahkan dikatakan sebagai salah satu kekuatan terbesar dari sebuah organisasi (Stewart dan Cantor dalam Shoemaker, 1991: 53).

\section{d Level Extramedia}

Shoemaker mengatakan bahwa pada organisasi bisnis gatekeeping hanyalah bagian dari proses memaksimalkan pendapatan dan meminimalkan pengeluaran. Peraturan yang mengatur proses gatekeeping di bentuk untuk memaksimalkan daya tarik pasar dan oleh karena itu peraturan gatekeeping dapat bervariasi tergantung dari karakteristik pasar (Shoemaker, 1991: 63).

\section{e Level Sistem Sosial}

Shoemaker berpendapat bahwa gatekeeping memiliki keterkaitan kuat dengan sistem sosial, ia sendiri merumuskan sistem sosial tersebut menjadi beberapa, antara lain budaya, kepentingan sosial, struktur sosial, dan ideologi (Shoemaker, 1991: 67, 68). Raymond Williams mendefinisikan ideologi sebagai sistem pemaknaan, nilai, dan keyakinan yang relatif formal dan terartikulasi serta dapat di abstraksi sebagai 'world view' (Williams dalam Shoemaker, 1991: 69).

\section{Citizen Journalism}

Shine Bowman dan Chirs Willis (2003: 9) mendefinisikan citizen journalism sebagai

“... the act of citizen journalism playing an active role in the process of collecting, reporting, analyzing, and disseminating news and information. The intent of this participation is ti provide independent, reliable, accurate, wide-ranging and relevant information that a democracy requires".

Ini artinya suatu tindakan dari Warga Negara/ Masyarakat yang berperan aktif dalam proses mengumpulkan, melaporkan, menganalisis dan menyebarkan berita atau informasi. Tujuannya adalah untuk memberikan informasi yang independen, reliable, akurat, mencakup luas dan relevan sesuai dengan dituntut oleh sistem demokrasi.

Citizen journalism (jurnalis warga) adalah warga biasa yang menjalankan fungsi selayaknya jurnalis professional yang pada umumnya menggunakan channel media baru yaitu internet untuk menyebarkan informasi dan berita yang mereka dapat. Dengan adanya sistem demokrasi saat ini masyarakat bebas berperan aktif memberikan informasi yang akurat.

Menurut Bentley (2008: 9) jurnalisme warga dapat diartikan sebagai

"...citizen journalism participation indeed predicted social capital production in the form of civic engagement, which can be meansured as participation, volunteering, and activism".

Yang artinya partisipasi jurnalisme warga memang diprediksi sosial produksi modal dalam bentuk keterlibatan masyarakat, yang dapat diukur sebagai partisipasi, sukarelawan, dan sebagai aktivisme.

Dalam hal ini di Radio Idola, masyarakat berpartisipasi dan aktif dalam memberikan informasi yang terjadi di lapangan. Informasi yang disampaikan oleh masyarakat via telepon. Masyarakat menyampaikan 
informasi tersebut secara sukarelawan tanpa imbalan apapun.

Citizen journalism (Jurnalisme Warga) pada umumnya adalah keterlibatan warga dalam menginformasikan sesuatu kejadian. Seseorang tanpa memandang latar belakang, pendidikan, keahlian dapat merencanakan, menggali, mencari, mengolah, melaporkan informasi (tulisan, gambar, foto, tuturan). Sedangkan Citizen Journalism di radio diperankan oleh para pendengar yang menginformasikan kepada penyiar radio. Para pendengar tersebut biasanya menginformasikan hal-hal yang bersifat aktual dan saat itu juga seperti kecelakaan, kemancetan, kebakaran dan lain-lain.

Begitu juga Radio Idola memiliki peran penting dalam memberikan informasi kepada masyarakat Semarang dan sekitarnya. Informasi yang disampaikan berasal dari laporan atau liputan secara langsung oleh seorang reporter. Namun, dengan keterbukaan informasi yang ada sekarang ini memungkinkan masyarakat atau pendengar memberikan informasi kepada media masa. Di Radio Idola, masyarakat atau pendengar diberikan ruang untuk menyampaikan informasi didalam setiap program yang disiarkan oleh Radio Idola. Penyiar melalui getekeeper akan merespon informasi yang disampaikan pendengar, baik melalui layanan pesan singkat atau via telepon. Jurnalisme warga di Radio Idola menjadi senjata ampuh, untuk mendapatkan perhatian dari masyarakat semarang dan sekitarnya, agar menjadi radio yang konsen terhadap pemberitaan. Pendengar ikut dilibatkan menjadi reporter dadakan. Didalam menyampaikan informasi yang dimilikinya. Dengan melibatkan pendengar sebagai reporter dadakan , maka pendengar akan semakin yakin dan percaya, bahwa radio idola memberikan ruang yang lebih kepada masyarakat, didalam perkembangan dunia jurnalisme warga.

\section{Metodologi Penelitian}

Metode yang digunakan Berdasarkan masalah dalam penelitian yang lebih menekankan proses, maka jenis penelitian dengan strateginya yang terbaik adalah penelitian kualitatif deskriptif. Menurut Bogdan dan Taylor dalam Lexy J. Moleong (2007: 4) mendefinisikan metodologi kualitatif sebagai prosedur penelitian yang menghasilkan data deskriptif berupa kata-kata tertulis atau lisan dari orangorang dan prilaku yang dapat diamati.

Strategi yang digunakan dalam penelitian ini adalah studi kasus terpancang karena hanya menyangkut satu radio, yaitu Radio idola Semarang. Disebut studi kasus terpancang karena permasalahan dan fokus permasalahannya sudah ditentukan lebih dahulu sebelum peneliti terjun menggali permasalahan dilapangan.(dalam Gunawan, 2005:31).

Sumber Data primer menurut Lofland dan Lofland dalam Lexy J. Moleong (2007: 157) sumber data utama dalam penelitian kualitatif ialah kata-kata, dan tindakan selebihnya adalah data tambahan seperti dokumen dan lain-lain. Berkaitan dengan hal itu pada bagian ini jenis datanya dibagi kedalam kata-kata dan tindakan, sumber data tertulis, foto, dan statistik.

Sumber data sekunder menurut Lexy J. Moleong (2007: 159) dikatakan bahwa sumber diluar kata dan tindakan merupakan sumber kedua. dilihat dari segi sumber data, bahan tambahan yang berasal dari sumber tertulis dapat dibagi atas sumber buku dan majalah ilmiah, sumber dari arsip, dokumen pribadi, dan dokumen resmi. 
Penelitian ini menggunakan pengembangan validitas trianggulasi seperti yang dikatakan Patton (dalam Gunawan, 2005: 24). Disebutkan ada empat macam trianggulasi, yaitu trianggulasi data, metode, peneliti, dan teoritis. Selanjutnya dalam penelitian ini digunakan trianggulasi data atau trianggulasi sumber, yaitu melihat sesuatu yang sama dari berbagai perspektif yang berbeda. Melalui trianggulasi data tersebut diperoleh informasi yang lengkap, mendalam, serta komprehensif.

\section{Hasil dan Pembahasan}

Sesuai dengan tagline dan ideology Radio Idola "Memandu dan Membantu" yaitu memberi informasi dari masyarakat baik lewat telepon, pesan singkat (sms) maupun pesan yang dikirim lewat media online (facebook, twiter, dan suara warga di website Radio Idola), sesuai tagline tersebut isi konten dari siaran radio idola adalah berisi informasi yang berguna dan bermanfaat untuk masyarakat. Saat siaran atau on air penyiar membacakan semua berita atau informasi yang dikirim oleh warga berupa pesan singkat (sms) maupun telepon. Radio Idola tidak membatasi pendengar memberikan berita atau informasi. Namun semua berita dan informasi dari pendengar harus tersebut tidak bohong (fiktif) dan identitas pemberi berita atau informasi harus diketahui jadi mereka dapat beranggung jawab dengan berita yang telah dikrim ke Radio Idola. Semua informasi yang disampaikan pendengar langsung disampaikan apa adanya seperti yang disampaikan oleh warga tanpa editan dari gatekeeper.

Dari hasil penelitian selama di Radio Idola mengenai Gatekeeper, kajian teori yang dapat digunakan adalah Level Individu ini Shoemaker menekankan pada pentingnya values yang dapat diartikan sebagai prinsip etis dan ideal mengenai 'apa seharusnya' (Bruce dan Yearley, 2006: 314). Shoemaker sendiri lebih banyak mencontohkan value tersebut dalam konteks Amerika, dimana jurnalis di sana dikatakan mengadopsi ide ethnosentrisme, altruistic democracy, responsible capitalism (Shoemaker, 1991: 43). Hal tersebut terlihat di Radio Idola dimana gatekeeper itu sendiri bukan jabatan, tetapi semua pekerja media yang memiliki kekuasaan untuk menyeleksi berita dapat menjadi gatekeeper. Yang dapat berperan sebagai gatekeeper yaitu Manajer Program, Supervisor news, dan Wartawan atau Reporter. Gatekeeper di Radio Idola tidak berdasarkan latar belakang pendidikan, menurut Yessi supervisor news yang berperan sebagai gatekeeper berpendapat, bahwa menjadi gatekeeper di Radio Idola berdasarkan pengalaman, relationsip, kemauan dan kemampuan. Berdasarkan pengalaman, Yesi bekerja di Radio Idola sudah sepuluh tahun, selama itu sudah menempati berbagai posisi sebelum diposisi gatekeeper yaitu awal terjun ke media radio sebagai penyiar, script writer, dan juga jurnalis. Berbagai prestasi ia peroleh pada tahun 2010 sebagai penulis terbaik Nasional (wilayah Indonesia Tengah) untuk Program Pengentasan Kemiskinan versi media Radio PNPM Mandiri, dan juara dua Nasional Lomba Karya Jurnalistik dan Fotografi 50 tahun Jasa Raharja versi media Radio kategori features. Untuk ralationsip yang dimaksud adalah menjaga hubungan baik dengan narasumber (instansi, swasta, pengusaha, pejabat publik, lsm, sesama jurnalis dari lintas media dan pendengar) yang bertujuan, agar dapat menambah wawasan, pengatahuan, dan akses agar lebih mudah untuk berkomunikasi. Sedangkan kemauan 
dan kemampuan yang dimaksud, ketika menghubungi narasumber gatekeeper mendapat kesulitan karena tidak dapat memberikan informasi dengan lengkap karena narasumber enggan menerangkan perihal yang diinginkan, sedangkan gatekeeper itu sendiri membutuhkan cover both side sebuah berita atau informasi agar tidak ada keberpihakan, oleh karena itu gatekeeper tidak boleh menyerah begitu saja harus meyakinkan pendengar bahwa Radio Idola mampu memandu dan membantu pendengar.

Seperti yang diungkapkan Yesi, menurut Sulis yang berperan sebagai Manager Program Radio idola yang sudah bekerja selama sembilan tahun di Radio Idola berdapat sama bahwa, mejadi Gatekeeper di Radio Idola tidak berdasarkan latar belakang pendidikan tetapi berdasarkan pengalaman yang dimiliki, walapun Sulis mempunyai latar belakang lulusan dari Sarjana Komunikasi namun tidak serta merta ia bisa langsung menjadi manager program, tetapi tetap melalui tahap untuk bisa menjadi seorang menager program. Berbagai pelatihan jurnalistik ia ikuti salah satunya ikut di Lembaga Pendidikan Pers LP3I dan berbagai prestasi ia peroleh salah satunya menjadi juara dua penulisan features yang diselenggarakakn oleh Buruh Dunia (ILO PBB). Beberapa posisi pernah ia tempati mulai dari reporter, penyiar, hingga menjadi manajer program sampai saat ini.

Wartawan atau reporter juga dapat berperan sebagai gatekeeper untuk memilih dan memilah berita yang layak untuk disiarkan secara live oleh penyiar. Aris yang berlatar belakang pendidikan dari Sarjana Hukum, tidak menutup kemungkinan dapat menjadi seorang reporter. Menurut Aris menjadi gatekeeper tidak berdasarkan latarbelakang pendidikan. Dari pengalaman akan belajar berbagai macam hal, berbagai pelatihan jurnalistik juga ia ikuti sebelum menjadi reporter saat ini, menjadi reporter Radio Idola yang dapat berperan sebagai gatekeeper, keuletan kerja yang menjadikan seseorang dapat menjadi gatekeeper, karena posisi getekeeper harus cepat dalam bertindak dan mengambil keputusan, menghubungi narasumber dan menjawab pertanyaan dari pendengar. Gatekeeper-lah yang menjadi ujung tombak sebuah siaran berita di Radio Idola. Oleh karena itu peran gatekeeper sangat penting, di Radio Idola memposisikan seorang gatekeeper tidak berdasarkan latarbelakang pendidikan tetapi berdasarkan pengalaman yang diperoleh masing-masing individu.

Sedangkan untuk level organisasi menurut Shoemaker level organisasional menjadi penting karena organisasi yang menentukan siapa yang mereka pekerjakan dan aturan mana yang diterapkan. Menurut perspektif organisasi seorang gatekeeper yang sukses adalah orang yang dapat secara sempurna merepresentasikan kepentingan organisasi tersebut (Shoemaker, 1991: 53). Pada level organisasi ini para karyawan di Radio Idola terikat aturan dalam satu visi dan misi, yaitu memiliki visi memberikan informasi yang berguna dan bermanfaat untuk masyarakat, sedangkan misinya adalah selalu meng update informasi yanng ada disekeliling untuk dibagikan kepada masyarakat. Implikasinya adalah berita yang masuk pada redaksi Radio Idola yang menyangkut kepentingan publik, yang berguna untuk masyarakat, dan akan disiarkan oleh Radio Idola secara live. Diantara masing-masing devisi seperti bagian (program, marketing, administrasi, IT) harus berkerja sama dengan baik, begitu pula peran gatekeeper di Radio Idola tidak 
berdiri sendiri, namun dibantu oleh penyiar, reporter, script writer yang membantu program acara sehingga terbentuk kerjasama agar menjadi satu mata rantai dalam suatu kerjasama yang baik.

Sementara Level Ekstramedia menurut Shoemaker, bahwa pada organisasi bisnis gatekeeping bagian dari proses memaksimalkan pendapatan dan meminimalkan pengeluaran. Peraturan yang mengatur proses gatekeeping di bentuk untuk memaksimalkan daya tarik pasar dan oleh karena itu peraturan gatekeeping dapat bervariasi tergantung dari karakteristik pasar (Shoemaker, 1991: 63). Hal ini dikarenakan tanpa adanya pengiklan media tidak dapat beroprasional secara maksimal, maka Radio Idola harus memiliki acara yang menarik pengiklan agar mau membelanjakan uangnya di Radio Idola. Namun dengan adanya pengiklan tidak terlalu menentukan isi berita yang disiarkan oleh Radio Idola. Sebagai mana pengeluaran Radio Idola sangat besar karena harus menghubungi narasumber oleh karena itu harus memaksimalkan pendapatan. Radio Idola juga bekerjasama dengan salah satu provider yang membatu meminimalkan pengeluaran telepon yang begitu besar karena dipakai setiap hari, oleh karena itu Radio idola selalu memberi inovasi-inovasi acara agar lebih menarik minat pengiklan.

Selain itu, berdasarkan Bentley, jurnalisme warga dapat diartikan sebagai '...citizen journalism participation indeed predicted social capital production in the form of civic engagement, which can be meansured as participation, volunteering, and activism". Yang artinya partisipasi jurnalisme warga memang diprediksi sosial produksi modal dalam bentuk keterlibatan masyarakat, yang dapat diukur sebagai partisipasi, sukarelawan, dan sebagai aktivisme (Bentley, 2008: 9). Demikian pula di Radio Idola Semarang, partisipasi masyarakat dalam satu hari bisa ratusan informasi yang dikirim oleh pendengar melalui telepon, pesan singkat (sms), dan media on line seperti (facebook, twiter, dan website) yang masuk melalui gatekeeper. Masyarakat memberikan informasi aktual soal lalulintas yang saat itu sedang dilalui, maupun permasalahan dan pengaduan pendengar. Informasi tersebut menjadi panduan bagi pendengar lainya yang akan melalui jalan tersebut. Respon masyarakat sangat baik mereka siap kapan aja dihubungi oleh Radio Idola untuk menyiarkan siaran secara on air. Sesuai dengan teori citizen jounalism menurut Bentley bahwa berita yang diterima oleh Radio Idola langsung dari masyarakat yang ikut berpartisipasi secara live untuk segera di on air-kan (Bentley, 2008: 9). Respon masyarakat sangat baik mereka siap kapan saja dihubungi Radio Idola secara langsung untuk siaran on air. Setiap informasi dari warga atau pendengar yang masuk ke gatekeeper dipilah dan diplih informasi yang layak untuk di on airkan. Dengan berdialog interaktif antara penyiar dengan warga yang diberi ruang untuk menyampaikan informasi secara live.

\section{Kesimpulan}

Apresiasi Radio Idola terhadap masyarakat yang memberikan informasi sangat baik, dengan melihat respon dan antusias warga yang begitu besar mengirimkan informasi ke Radio Idola. Selalu konsisten memberikan informasi dan selalu berpartisipasi dalam memberikan informasi yang bermanfaat bagi masyarakat.

Sementaraitu, dalam proses
seleksi berita di lakukan oleh


gatekeeping di Radio Idola, dalam pemilihan berita atau informasi dari masyarakat. Gatekeeper yang bertugas mengolah informasi yang masuk sampai disiarkan, menjawab pertanyaan dan memberikan solusi. Berita atau informasi didapat melalui pendengar yang menyampaikan informasi melalui telepon, hot line sms idola dan melalui media jejaring internet (facebook, twiter, website Radio Idola), dalam hal ini pendengar yang terus memberikan informasidisebut dengan citizen journalism, rata-rata masyarakat memberikan infromasi yang aktual seperti arus lalulintas yang saat itu sedang dilalui dan menjadi panduan bagi pendengar Radio Idola lain yang akan memelalui jalan tersebut. Informasi-informasi tersebut diseleksi oleh gatekeeper jika informasi itu layak siar seperti informasi yang fakta, dapat dipertanggung jawabkan dan bermaanfaat untuk masyarakat. Sedangkan informasi yang tidak layak siar yaitu informasi yang tidak jelas dimana kejadiannya, pengirim informasi tidak jelas. Selanjutnya jika informasi itu layak siar jurnalis warga akan diberikan ruang untuk dapaton air dalam memberikan informasi secara live.

\section{Daftar Pustaka}

Bentley, Clyde H. 2008. Citizen Journalism:Back to the Future. Conference on the Future of Journalism. Cambridge.

Gunawan Witjaksana. 2009. Pokokpokok Pikiran Dalam Metodologi Penelitian komunikasi kualitatif. Buku Ajar Ilmu Komunikasi USM.

J.D. Lasika. 2003. Shane Bowman and Chris Willis and The Media Center at the American Press Institute. We Media: How Audiens Are Shaping the Future Of New And Information. Media Center.

Moleong, L. J. 2006. Metodologi Penelitian Kualitatif. Bandung: PT. Remaja Rosdakarya.

Shoemaker, Pamela J. 1991. Communication Concept 3: Gatekeeping. Newbury Park, California: Sage.

Shoemaker, Pamela J and Stephen D. Reese. 1996. Mediating The Massage: Theories of Influences on Mass Media Content. Logman. New York

Steve Bruce, \& Steven Yearley. 2006. The Sage Dictionary of Sociology.London: Sage Publication. 